\title{
Project description and crowdfunding success: an exploratory study
}

\author{
Mi (Jamie) Zhou ${ }^{1}$ (D) B Baozhou Lu ${ }^{2} \cdot$ Weiguo (Patrick) Fan ${ }^{1} \cdot$ G. Alan Wang ${ }^{1}$
}

Published online: 7 December 2016

(C) The Author(s) 2016. This article is published with open access at Springerlink.com

\begin{abstract}
Existing research on antecedent of funding success mainly focuses on basic project properties such as funding goal, duration, and project category. In this study, we view the process by which project owners raise funds from backers as a persuasion process through project descriptions. Guided by the unimodel theory of persuasion, this study identifies three exemplary antecedents (length, readability, and tone) from the content of project descriptions and two antecedents (past experience and past expertise) from the trustworthy cue of project descriptions. We then investigate their impacts on funding success. Using data collected from Kickstarter, a popular crowdfunding platform, we find that these antecedents are significantly associated with funding success. Empirical results show that the proposed model that incorporated these antecedents can achieve an accuracy of $73 \%$ (70\% in Fmeasure). The result represents an improvement of roughly 14 percentage points over the baseline model based on informed guessing and 4 percentage points improvement over the mainstream model based on basic project properties (or $44 \%$ improvement of mainstream's performance over informed guessing). The proposed model also has superior true positive and true negative rates. We also investigate the timeliness of project data and find that old project data is gradually becoming less relevant and losing predictive power to newly created projects. Overall, this study provides evidence that antecedents identified from project descriptions have incremental
\end{abstract}

Mi (Jamie) Zhou

mizhou@vt.edu

1 Pamplin College of Business, Virginia Polytechnic Institute and State University, Blacksburg, VA 24061, USA

2 School of Economics \& Management, China University of Petroleum, Qingdao 266580, China predictive power and can help project owners evaluate and improve the likelihood of funding success.

Keywords Crowdfunding · Content analysis · Persuasion · Empirical study $\cdot$ Predictive model

\section{Introduction}

In recent years, crowdfunding has emerged as a revolutionary financing model that allows small entrepreneurs to raise funding in the early stages of their projects, particularly those that may otherwise struggle to obtain capital (Kuppuswamy and Bayus 2013; Belleflamme et al. 2014). Today, there are approximately 1250 active crowdfunding platforms across the world, which together channeled $\$ 16.2$ billion in 2014 , representing a $167 \%$ increase from $\$ 6.1$ billion in 2013 (Massolution 2015). Having their project successfully funded is crucial to project creators as it provides not only initial funds for project development but also access to valuable future resources, and eventually turn their projects into successful entrepreneurial organizations (Mollick 2014). Previous research shows that only $45 \%$ of the projects on these platforms are successfully funded (Greenberg et al. 2013; Mollick 2014). As a result, identifying general antecedents of funding success (i.e., successfully funded) has been of great interest to researchers because it can provide insights to project creators to maximize their funding success (Greenberg et al. 2013; Xu et al. 2014).

It is natural to believe that one of important antecedents of funding success is the quality of project, and previous research on crowdfunding has suggested that project quantity is positively associated with the likelihood of funding success (Mollick 2014). However, the project quality is a latent construct and is measured from different aspects such as innovation, market condition, management team and so on. This 
measurement requires high level of expertise and experience in venture investment and it is usually done case by case. Consequently, existing studies on antecedent of funding success mainly focus on project properties that may directly or indirectly impact the funding success. For example, research has found that project properties ${ }^{1}$ such as the funding goal, campaign duration, number of Facebook friends of the project creator, etc. are associated with funding success (Agrawal et al. 2011; Greenberg et al. 2013; Z. Li and Duan 2014; Mollick 2014; Xu et al. 2014; Kuppuswamy and Bayus 2015).

Although existing research has identified an impressive list of antecedents that are associated with funding success, our primary criticism is the fact that they only focus on basic project properties, and that the information related to project descriptions is largely ignored. This paper tries to fill the gap by highlighting the importance of project descriptions and identifying influential antecedents of funding success under a theoretical guidance. Similar to traditional business plans, project descriptions are highly recommended to include the following information: what you are trying to do, how you will do it, how the funds will be used, qualifications to complete this project, people on the team, and how far along your project is (Kickstarter 2016). Previous entrepreneurship literature has evidenced that nascent entrepreneurs manage impressions and persuade business angels by manipulating language use of business plans (e.g., tone and style), in hoping to increase the likelihood of being selected for further consideration or getting funded (Chan and Park 2015; Parhankangas and Ehrlich 2014). Owners of crowdfunding projects are essentially entrepreneurs and have similar funding needs. We conjecture that they have the propensity to use project descriptions to promote their projects (products) and persuade backers to make a financial contribution.

Following the previous research on traditional business plans (Chen et al. 2009), we view the process by which project owners secure funding from backers as a "persuasion process" and introduce the unimodel of persuasion into crowdfunding domain. However, the primary interest of this paper is not to test unimodel of persuasion, but to utilize its theoretical guidance and explore potential antecedents of funding success. Although there are other persuasion theories such as Elaboration Likelihood Model (ELM), we choose unimodel because it clearly indicates the sources of influential factors and it has been successfully applied to entrepreneurship literature to study the persuasion process of venture capitalists' funding decisions (Chen et al. 2009). Unimodel of persuasion classifies persuasive information into issue-relevant (the content of a message) and issue-irrelevant (cues other than the message itself), and it argues that these two types of information are functional equivalent in persuasion, though they may

\footnotetext{
${ }^{1}$ In this study, the terms property, antecedent, factor, and variable are interchangeable, unless otherwise specified.
}

be quantitative different (Kruglanski 1989; Kruglanski et al. 2006; Chen et al. 2009). Guided by unimodel of persuasion, we identify five potential antecedents of funding success. Three of them (length, readability, and tone) are identified from the content of project description (issue-relevant) and two of them (past experience and past expertise) are from the trustworthy (issue-irrelevant) of project descriptions.

We then study whether these five newly identified antecedents are statistically influential on funding success and whether such influence is practically meaningful. Our logistic regression results show that each of these antecedents is significantly associated with funding success. When these five antecedents are incorporated into a predictive model (logistic), the results of $\mathrm{N}$-Fold cross-validation tests indicate that the proposed model can predict funding success with an accuracy rate (F-measure) of $73 \%(70 \%)$. The average accuracy rate (F-measure) of the mainstream model is around $69 \%$ (66\%), and baseline model around $59 \%(57 \%)$. This indicates that the proposed model has an improvement of roughly 14 percentage points (rounded) over the baseline model based on informed guessing and 4 percentage points improvement over the mainstream model based on basic project properties. The differences among these three models are statistically significant under the t-test. More importantly, considering that the mainstream model only beats the baseline model by 9 percentage points ( $57 \%$ to $66 \%$ ), the 4 additional percentage points (66\% to $70 \%$ ) improved by our proposed model is fair significant, representing $44 \%$ (i.e., 4 divided by 9) of mainstream's performance over informed guessing. These results together show that our newly introduced variables have significant and practical impacts on the funding success of projects.

Additionally, crowdfunding environment has experienced tremendous changes since its inception, from perspectives such as platform functions, users and policy, and so on. For example, the numbers of users and projects have grown drastically (Kickstarter 2014b), which change the competition environment of crowdfunding. Additionally, both backers and owners are likely to change their behaviors through their use of the crowdfunding platforms. These changes make us wonder 1) whether the project data in earlier years have become "out of date" and have less power to predict funding success of future projects, and 2) whether the sub-sample of project data right before the projects being predicted contains the most relevant information and have higher predictive power. To answer these questions, we investigate the timeliness of project data and provide evidence that old project data is gradually becoming less relevant and losing predictive power to newly created projects. Overall, our results provide insights to researchers, project owners, and backers to better study and use crowdfunding platforms.

This rest of the paper is organized as follows. We first review literature related to the antecedents of crowdfunding success and the unimodel of persuasion. We then propose a new 
method based on the unimodel to quantify the influence of project descriptions based on content analysis. We present and discuss our empirical results using data sample collected from a popular crowdfunding site, Kickstarter. Finally, we provide conclusions and discuss opportunities for future research.

\section{Background and literature review}

\subsection{Crowdfunding models and platforms}

According to the context and nature of the funding effort, there are mainly four models of crowdfunding (Belleflamme et al. 2014). The first model is patronage-based, where supporters expect no direct return from their contributions or donations. The second one is lending-based, where the supporters expect some rate of return on their capital invested. The third one is rewardbased, where supporters receive a reward for backing a project. The reward can simply be a mention/credit in a movie or a prototype (earlier version) of a product. The last one is equity based, where the supporters are treated as investors and are given certain shares of future profit of the project (Mollick 2014).

This study focuses on the reward-based crowdfunding, in which there are two dominant models regarding how funds are raised and distributed to project owners, represented respectively by two popular crowdfunding platforms, Kickstarter and IndieGoGo. Funds raised on Kickstarter follows a rule called all-or-nothing, which means no one will be charged for a pledge towards a project unless it reaches its funding goal (Kickstarter 2014a). On the other hand, IndieGoGo allows creators to keep the money pledged even the project fails to meet its goal (IndieGoGo 2014). While the all-or-nothing policy leads to greater motivation on Kickstarter, it's nice to at least get some money as opposed to none. Kickstarter charge $5 \%$ commission fee of the funds raised for each project and IndieGoGo between 4 and $9 \%$ (when the goal is not met).

\subsection{Antecedents of funding success}

Existing research has suggested that crowdfunding projects mostly succeed by narrow margins, or else fail by large amounts, and that crowdfunding success appears to be linked to project quality, i.e., projects of a higher quality level are more likely to be funded (Mollick 2014). However, the quality of a crowdfunding project is not easy to measure because individual backers generally lack relevant expertise owned by venture capitalists (VCs) and their contribution decisions are usually based on factors such as feeling and preference which, because of the limited backer data on the crowdfunding platform, ${ }^{2}$ are difficult to evaluate and quantify.

\footnotetext{
${ }^{2}$ For example, Kickstarter only provide the total number of bakers, the information of each backer is not provided.
}

As an alternative, researchers turn to other factors that may directly or indirectly influence the funding success of a project. Some researchers find that project properties, such as project category, funding goal, and campaign duration, are associated with funding success. Others show that the existence of images or videos in project introduction is associated with funding success (Greenberg et al. 2013; Mollick 2014). Studies have also shown that a project owner's social influence, proxied by the numbers of friends on social networks such as Facebook, has an impact on funding success (Mollick 2014). Furthermore, researchers find a strong geographic influence in crowdfunding projects: project owners are more likely to propose those projects reflecting the underlying cultural products of their geographic areas (e.g., a project related to country music in Nashville, Tennessee) (Agrawal et al. 2011; Mollick 2014). They suggest that the nature of the population in which founders operate is related to funding success (Kuppuswamy and Bayus 2013; Z. Li and Duan 2014). More recently, by studying the reciprocity effect on crowdfunding, Zvilichovsky et al. (2015) provide evidence that project owners' backing-history has a significant effect on financing success: projects initiated by owners who have previously supported others have higher success rates, attract more backers and collect more funds.

\subsection{Project description and persuasion theory}

Although existing research on antecedents and funding success contributes greatly to our understanding of crowdfunding, few studies have focused on the project descriptions. Research in venture literature has evidenced that "business plan serves as an important indicator of a venture's potential for success." (Chen et al. 2009, p. 202) Despite the difference between the funding environments, project descriptions are similar to traditional business plans in terms of both content and function (Kickstarter 2016). On the one hand, the project description is one of the most important information sources for backers to evaluate a project and make their funding decisions. Earlystage investments typically involve unproven technologies, unfinished products, and services. Thus, factual evidence pertaining to the new venture and its quality is often unavailable (Parhankangas and Ehrlich 2014). On crowdfunding platforms, backers "pre-order" products before their existence, and these products are "promised" to be delivered in a future day. Backers usually have no control over the project development, and there is little external information such as customer reviews for backers to evaluate a product or an owner. On the other hand, project description is one of the few available tools for project owners to communicate with potential backers and promote their projects. This is especially true before the project is launched. Given the fact that the number of crowdfunding projects is increasing dramatically in recent years, the competition for backers' attention is becoming 
increasingly fierce (Mollick 2014). This highlights the importance of project descriptions for both project owners and backers on crowdfunding domain. We conjecture that project owners have the propensity to use project descriptions as marketing tools to influence potential backers' contribution decisions.

There are only a few studies that have examined information content of project descriptions in the context of crowdfunding. These studies, however, either use a case study approach relying on small samples (Ordanini et al. 2011) or simply include all phrases as predictive variables (Mitra and Gilbert 2014). To identify the potential influential antecedents from project descriptions, we need to understand how information is processed by backers to form their funding decisions. On this point, social judgment and persuasion research offer potential insights. For example, Parhankangas and Ehrlich (2014) find the business angels' funding decisions are influenced by the language use of business proposals (plans). In another study, Chen et al. (2009) use a persuasion theory of the unimodel and investigate the extent to which venture capitalists" perceptions of "entrepreneurial passion" from business plans influence their investment decisions. Following their approaches, we conceptualize the process by which project owners secure funding from backers through project descriptions as a persuasion process, and employ the unimodel of persuasion to identify potential antecedents of funding success.

Although the unimodel differs from other established paradigms of persuasion such as dual-process model of ELM (Petty and Cacioppo 1986; Petty et al. 2002; Rucker and Petty 2006), it has received greater recognition and acceptance in the literature in recent years (Chen et al. 2009; Catellani and Alberici 2012; Suárez-Vázquez and Quevedo 2015). Dualprocess models suggest that influence is formed from two routes, namely, central route and peripheral route, and that the influence of two routes is both qualitatively and quantitatively different. In other words, individuals have a higher motivation or cognitive ability tend to rely more on the central route, and the influence of central route is more enduring than that of the peripheral route. Unimodel of persuasion also classifies information into two types: issue-relevant (the content of a message) and issue-irrelevant (cues other than the message itself) (Chen et al. 2009). However, unimodel only suggests the quantitative difference, not the qualitative difference, of the influence of different information. In other words, unimodel assumes that the processing of issue-relevant information and issue-irrelevant information share the same route (individuals subjectively decides which information qualifies as their basis for persuasion-based decisions), and they have the same enduring effect on individual's decision.

Consistent with previous research on the influence of business plans on venture capitalists' funding decisions (Chen et al. 2009), we believe that the unimodel explains better the backers' decision-making process because it emphasizes the subjectivity and equality of information basis and parsimoniously captures the persuasion process. In the context of crowdfunding, a backer's funding decision is determined by what the backer believes to be the basis for his/her judgment. For example, if a backer personally knows the project owner, he/she may rely less on the project description itself and use his/her personal experience as the basis to make a funding decision; otherwise, the backer may be more likely to use project description as the basis to make the decision. In addition, both persuasion and funding decision on crowdfunding are not a "one-time" thing. Backers usually get to know the project at a different time; Kickstarter provides backers with tools (web pages) to monitor projects they have backed (Kickstarter 2014a), and backers can re-visit the project descriptions and get "influenced" throughout the campaign. More importantly, Kickstarter allows backers to make and change their decisions (contribute, cancel, or re-contribute) anytime before the campaign is ended (Kickstarter 2014a). In other words, project description is accessed by backers at the different time point (or multiple times by a backer), and their funding decision can be formed at any time point before the campaign is ended. However, the ending time of a campaign is fixed and is the same to every backer; this setting makes the enduring effect of influence less meaningful in the context of crowdfunding. In summary, unimodel of persuasion provide us with a theoretical guidance regarding the information sources of potential antecedents of funding decisions, without dealing the subtle details of influencing process.

In this study, the potential antecedents of funding success are investigated at the aggregated level (backer population), not at the individual backer level. Unimodel of persuasion is an individual level theory and mainly links the influential antecedents to individual backer's funding decision. Following the previous literature (Baum et al. 2001; Baron 2008; Chen et al. 2009), we extend this link to include funding success at the aggregated level. Unimodel suggests that a antecedent can have a strong influence on a backer's funding decision. We argue that, however, if a antecedent has an influence on enough backers' funding decisions, ${ }^{3}$ at the aggregated level, these funding decisions will lead to a higher likelihood of funding success. Previous persuasion and venture literature have evidenced a link between entrepreneur's traits and venture success and growth (Baum et al. 2001; Baron 2008; Chen et al. 2009). Especially, using the unimodel of persuasion, Chen et al. (2009) find that the affective and cognitive passion revealed from traditional business plans are positively associated with venture success. They further explain that these traits

\footnotetext{
${ }^{3}$ Theoretical, decisions can be both positive and negative. In this study, we mainly focus on positive funding decisions, in line with the role of project descriptions.
} 
can make "entrepreneurs more persuasive," thus "these entrepreneurs had a higher probability of achieving success in new ventures." (Chen et al. 2009, p. 201) The argument we used to extend the link is also consistent with marketing and advertising literature that persuasion (or response) occurs at individual level, but the overall success (of marketing and advertising) is evaluated at the aggregated level (e.g., market-level sales) (Sun et al. 2010; Venkatraman et al. 2014).

\section{Methodology}

Existing research on crowdfunding success are generally interested in evaluating the performance (predicting accuracy) of different models, assuming each model using the same set of antecedents. For example, Greenberg et al. (2013) evaluates the performance of various decision tree algorithms and support vector machines with different kernel functions. Specifically, they evaluate the performance of radial basis, polynomial and sigmoid kernel functions with varying costs for support vector machines. For decision trees, they further evaluate different learning algorithm variations such as J48 Trees, Logistic Model Trees, Random Forests, Random Trees and REPTree. Then they choose the highest performing set of algorithms and boost them using the AdaBoost algorithm to see if accuracy is improved. In other words, existing research focuses on the model level, trying to find the best models with optimized parameters to achieve the highest performance. Our study, on the other hand, focuses on the antecedent level and tries to identify additional antecedents from a theoretical perspective (i.e., the unimodel of persuasion), and evaluates whether they have the incremental power to predict funding success. These additional contributing antecedents can then be applied to different predictive models.

\subsection{Identifying exemplary antecedents of funding success}

This study introduces the unimodel of persuasion into crowdfunding domain. However, the primary purpose of this study is not to test the unimodel theory, but to use the theory as a guidance and identify potential antecedents of funding success beyond basic project properties. In addition, this study doesn't mean to identify a complete set of antecedents from project description, rather, we use exemplary antecedents to demonstrate that unimodel can be used to facilitate our understanding of persuasion process and uncover potential antecedents. We choose exemplary antecedents based on following criteria: 1) the antecedent must be closely related crowdfunding context; 2) the antecedent must be aligned with unimodel of persuasion; 3 ) the antecedent can be reliably extracted or calculated automatically, and 4) the antecedent must be widely used in literature.
Unimodel of persuasion suggests that backers' funding decisions are influenced by the content of project description (issue-relevant message) and cues other than project description itself (issue-irrelevant message) (Chen et al. 2009). Since the project description of crowdfunding project shares the similar content and role of traditional business plans, we identify potential antecedents based on previous research on traditional business plans (or investment proposals). For the content of project description, research on traditional investment proposals finds that language use can positively influence business angels' decision and increase the likelihood of being funded (Parhankangas and Ehrlich 2014). So we first identify three exemplary antecedents based on language use of project description through a content analysis. Similarly, for the cues other than project description itself, research on traditional business plans find that entrepreneur's traits such as tenacity, proactivity and passion are associated with venture success and growth (Baum et al. 2001; Chen et al. 2009). So we identify two exemplary antecedents based on project owners' traits. These exemplary antecedents are discussed in more detail below.

The three exemplary antecedents identified from the language use of project description are length, readability, and tone. Length captures the amount of information project owner provided. Since crowdfunding projects typically involve unproven technologies, unfinished products, and services, there is litter external information regarding the factual evidence pertaining to their final products and quality. Project owners thus are encouraged to provide sufficient information for backers to evaluate the project, increase backers' confidence, and earn their trust (Kickstarter 2016). So we posit that length is a potential antecedent of funding success. Readability (not legibility) captures the easy of understanding of project description. Because of its importance on effective communication, readability has been advocated by the government, business, and other organizations. For example, The U.S. Department of Defense uses the Reading Ease test as the standard test of readability for its documents and forms, and Florida requires that the readability of life insurance policies must be greater than a set score (Wikipedia 2015). So we posit that readability is also a potential antecedent of funding success. Lastly, tone captures the general attitude used by project owner to describe their products or services. Research on business plans has evidence that entrepreneurs use moderate positive language in order to attract investors (Parhankangas and Ehrlich 2014). So we believe that tone could also be a potential antecedent of funding success.

The two potential antecedents identified from project owners' traits are past expertise and past experience. These two traits demonstrate the competence and trustworthy of project owner and increase their likelihood of funding success. Because of potential costs, backers very often do not want to support a project that is unlikely to 
succeed (Li and Duan 2014). These costs can be associated with backer's disutility from having his or her money locked in the project or potential risk that rewards cannot be delivered as promised. Past expertise captures the achievement and success of the previous project creating actives. Higher expertise generally leads to a higher likelihood of funding success. Past experience captures project owners' previous backing and creating activities on the crowdfunding platform. On the one hand, backing a project will make a project owner think from a backer's perspective, thus having a better understanding of information needs of backers. This experience may increase his/ her competence to create a better project description. On the other hand, research has evidenced a reciprocity effect on crowdfunding that project owner with more backing activates are more likely to receive reciprocal backing from project owners they backed (Zvilichovsky et al. 2015). In other words, project owners can accumulate social capital by backing projects and at least partially cash it out when they raise funds for their own projects. In either case, past backing activities are likely to increase funding success. Additionally, project owners can learn from both successful and failed project they created in the past by enhancing the strengths and improving weaknesses. As a result, past creating activities are also likely to impact funding success. In summary, both past expertise and past experience are potential antecedents of funding success.

\subsection{Predictive model and measures}

Because each project can be classified as either a success (reaching the funding goal when the campaign is completed) or a failure (not reaching the funding goal when the campaign is completed), we build a logistic regression model to study the influence of project descriptions on the success of a funding project. We use logistic regression model, instead of other binary classification models, for the following reasons. First, as discussed above, our primary purpose is to identify additional contributing factors, not to evaluate the model performance. So the selection of model is based on whether the model has the capability to evaluate factors. Second, we want to analyze each newly introduced factors quantitatively and see whether they have significant and incremental predictive power to funding success. The significance test of coefficients of logistic regression model provides us with such a capability. Third, logistic regression model has widely used in binary classification and has competitive performance results with other traditional classification models such as Support Vector Machines (Hua et al. 2007; Abrahams et al. 2014). All variables or antecedents used in this study are organized and described in Table 1.
As shown in Table 1, the potential antecedents that influence funding success are arranged into two categories, namely, previously identified and newly introduced antecedents. Those newly introduced antecedents are further organized into content and trustworthy cue of project descriptions, according to unimodel of persuasion. In order to evaluate the incremental contribution of those newly introduced antecedents in determining funding success, we control for other major antecedents of funding success identified in previous research, such as project category, goal and duration (Greenberg et al. 2013; Mollick 2014). Our model is shown below.

$$
\begin{aligned}
\operatorname{logit}(\text { Success }) & =\beta_{0}+\beta_{1} \text { length }+\beta_{2} \text { readability }+\beta_{3} \text { tone }+\beta_{4} \text { tone }^{2} \\
& +\beta_{5} \text { pastExperience }+\beta_{6} \text { pastExpertise }+\beta_{7} \text { goal } \\
& +\beta_{8} \text { duration }+\beta_{9} \text { rewards }+\beta_{10} \text { numImages } \\
& +\beta_{11} \text { numVideos }+\varepsilon
\end{aligned}
$$

Where success takes a value of either 0 or 1 , indicating whether a project is successfully funded. Following the previous literature, we measure the amount of information (length) by using the number of words in the project description (Wang et al. 2011; Zhou et al. 2015). We measure the ease of understanding (readability) by calculating the readability score of the project description. Specifically, we use Gunning fog index (hereafter Fog Index) to measure the readability of project description. The Fog index was developed by Robert Gunning ("Gunning fog index," 2015) and has been widely used in literature (F. Li 2008; Wang et al. 2011; Zhou et al. 2015). Fog index proposes that, assuming everything else to be equal, more syllables per word or more words per sentence make a document harder to read. For example, texts such as formal financial reports generally have a Fog index greater than 16 (F. Li 2008), and documents for a wide audience generally need a fog index less than 12 ("Gunning fog index," 2015). Please note that a higher value of the Fog index corresponds to a lower level of readability. So we intentionally reverse the sign of Fog Index to reflect the direction. Specifically, readability is calculated as follows:

readability $=-\left[\left(\frac{\text { words }}{\text { sentences }}\right)+100 \times\left(\frac{\text { complex words }}{\text { words }}\right)\right] \times 0.4$

Following the tone management literature (F. Li 2008; Davis et al. 2012; Huang et al. 2013), we measure the tone as the percentage difference of positive and negative words in the project description. Specifically, it is calculated as follows:

tone $=\frac{\text { positive words }- \text { negative words }}{\text { total words }}$

The positive and negative words used in the formula are defined in Harvard-IV dictionary, which has been widely used to measure the tone reflected in textual contents (Davis et al. 2012; Huang et al. 2013). Because of the nature of marketing and persuasion, we expect that the project description usually 
Table 1 Variable (antecedent) description

\begin{tabular}{|c|c|c|c|}
\hline Type & Source & Variable & Definition \\
\hline \multirow{5}{*}{$\begin{array}{l}\text { Newly Identified } \\
\text { Antecedents }\end{array}$} & \multirow[t]{3}{*}{ Content of project description } & length & The number of word contained in project description. \\
\hline & & readability & $\begin{array}{l}\text { The ease of understanding of project description, measured by using } \\
\text { readability index. }\end{array}$ \\
\hline & & tone & The ratio of positive and negative words in project description. \\
\hline & \multirow{2}{*}{$\begin{array}{l}\text { Trustworthy cues (project } \\
\text { owner traits) }\end{array}$} & pastExperience & The number of projects previously created and backed by the owner \\
\hline & & pastExpertise & The rate of projects successfully funded. \\
\hline \multirow{9}{*}{$\begin{array}{l}\text { Previously Identified } \\
\text { Antecedents }\end{array}$} & \multirow[t]{9}{*}{ Control Variables } & goal & Project goal, the amount owner seeks to raise using crowdfunding. \\
\hline & & duration & The number of days for which a project accepts funds. \\
\hline & & FBConnected & $\begin{array}{l}\text { Whether the project owner has linked or created a Facebook page for } \\
\text { the project. }\end{array}$ \\
\hline & & FBFriends & The number of Facebook friends a project owner has. \\
\hline & & numImages & The number of images embedded in the project page. \\
\hline & & numVideos & The number of videos embedded in the project page. \\
\hline & & rewards & The number of pledge levels \\
\hline & & year & The year a project launched ,not the year the project completed. \\
\hline & & category & The category of the projects. \\
\hline
\end{tabular}

has a net positive tone. In other words, more positive words than negative words are used in project descriptions. However, previous research has found that the venture capitalists preferred "moderate use of positive language" and evidenced a curvilinear relationship between positive language and funding success. So we add a quadratic term of tone to the model.

As the reason discussed above, since project owners can learn and benefit from both their backing and creating activities, we measure past experience (pastExperience) by using the number of projects previously either created and backed by the owner, before the one being investigated. Finally, we measure past expertise (pastExpertise) by using the ratio of total funds raised and total goals required for all previous projects ended before the one being investigated. For example, assuming an owner has created three projects; when we investigate his past expertise by the time he is creating the third project, we should only consider the total funds raised and the total funds required for the first two projects, assuming both projects have been completed.

\section{Empirical results}

\subsection{Data sample}

We collected real crowdfunding project data from Kickstarter. com to carry out our empirical analysis. We use Kickstarter mainly for two reasons. First, Kickstarter is a popular and prevalent crowdfunding platform. Founded in 2009, Kickstarter has become one of the largest crowdfunding platforms in the world. It has more than nine million backers, and three million of them are repeat backers. As of today, more than 93,000 projects have been successfully funded, and more than two billion dollars have been raised (Kickstarter 2015). Second, the majority of research on crowdfunding uses Kickstarter data (Greenberg et al. 2013; Li and Duan 2014). This makes the comparison of our results against those previous reported more meaningful and reliable.

Kickstarter doesn't provide a pubic API (Application Program Interface), and the non-live projects (e.g., completed, canceled, etc.) are not directly searchable. However, live projects are organized in category and are convenient to navigate. Our data collection mainly consists of two steps. First, started in late 2012, we scraped the those "live" projects from Kickstarter websites by using a specially developed crawler. The crawler visited the website every other day and captured all live projects newly launched. Second, we scraped project data in early years based on those live projects already collected. Project's profile page contains the historical projects created and backed by the owner, and comments and updates contain backers' information which leads to other projects they backed. Similar to the approach used by Zvilichovsky et al. (2015), we used those "live" projects as seed and recursively iterate from projects to backers and backers to projects until the number of newly discovered projects per iteration converged. This step was only performed once a while when a big enough number of new projects were scrapped.

Our data sample covers all the projects from 2009 to November 2014. We excluded those funding projects that were still ongoing (6559 projects). In addition, we excluded those projects that were canceled ( 15,116 projects), purged (36 projects), and suspended (584 projects). Purged and 
suspended projects were usually handled by Kickstarter according to its policy or terms of use. Projects were canceled by owners for a variety of reasons. It's possible that majority of projects were canceled because they were unlikely to reach the funding goals and project owners want to avoid the dismal end (stonemaiergames.com 2013). A brief examination also finds that many projects were canceled because they were simply testing projects, with unreasonable low funding goal (e.g., \$1, $\$ 2$ ) or duration (e.g., 1 day). And some projects were canceled because project owners want to make necessary improvement and re-launch the project, or "amazing partners reached out" during the campaign (needwant.com 2016). It's also interesting to find out some projects were canceled even after successfully funded because of unforeseen changes from either project owners or backers (themarysue.com 2016). These projects were not treated as failed projects because they were not typically failed projects. We also followed a previous study (Mollick 2014) and removed those projects with a funding goal below $\$ 100$ (1982 projects) or above $\$ 1,000,000$ (294 projects), because those extremely small or large projects may have characteristics very different from the majority of projects. We finally removed those projects with less than 100 words in their descriptions, because, upon inspection, they are either incomplete or represent non-serious efforts to raise funds. Our final data sample consists of 151,752 projects across all 15 funding categories. These steps are summarized in Table 2.

Table 3 shows the descriptive statistics for variables used in this paper. On average, the projects in our sample have an average funding goal of $\$ 15,126$, with half of them less than $\$ 5000$. The average (median) campaign duration is 34 (30) days; $47 \%$ of projects have at least an image, with the average (median) number of 4.67 (1); and $80 \%$ of projects have at least a demo video, with the average (median) of 1.18 (1). The results also show that the descriptions have an average (median) length of 646 (482) words, are generally positive (with a net positive tone), and are easy to understand (with fog index around 13). In addition, although owners usually have some past experience, with several projects backed or created, their past expertise is very limited. Averagely, they have raised 22 present of required funds on their previous

Table 2 Sample selection and description

Sample projects

\begin{tabular}{ll}
\hline All projects scraped & 183648 \\
Less live projects & 6559 \\
Less canceled, purged and suspended projects & 15736 \\
Less projects with goal less than 100 or above 1,000,000 & 2276 \\
Less projects with invalid project description (missing, less than & 7325 \\
$\quad 50$ words, etc.) & 151752 \\
\hline Total sample projects & \\
\hline
\end{tabular}

Table 3 Descriptive statistics

\begin{tabular}{lllllll}
\hline Variables & Min & 1st Q & Median & Mean & 3rd Q & Max \\
\hline length & 100 & 296 & 482 & 646.00 & 812 & 30280 \\
readability & -19.68 & -14.69 & -12.92 & -13.08 & -11.33 & -5.10 \\
tone & -0.22 & 0.04 & 0.07 & 0.07 & 0.10 & 0.48 \\
pastExperience & 0 & 1 & 3 & 6.00 & 6 & 1267 \\
pastExpertise & 0.00 & 0.00 & 0.00 & 0.22 & 0.00 & 9.97 \\
goal & 100 & 2000 & 5000 & 15126 & 12000 & 100000000 \\
duration & 2 & 30 & 30 & 34.00 & 39 & 90 \\
rewards & 1 & 6 & 9 & 9.00 & 12 & 250 \\
FBFriends & 0 & 24 & 383 & 503.00 & 755 & 7797 \\
hasImage & 0.00 & 0.00 & 0.00 & 0.47 & 1.00 & 1.00 \\
hasVideo & 0.00 & 1.00 & 1.00 & 0.80 & 1.00 & 1.00 \\
numImages & 0 & 0 & 1 & 4.67 & 6 & 248 \\
numVideos & 0 & 1 & 1 & 1.18 & 1 & 25 \\
\hline
\end{tabular}

projects, if any (more than $75 \%$ of projects are created by the first-time owners).

In the follow sections, we present our empirical analysis results from three aspects. First, we briefly discuss the current status of crowdfunding on Kickstarter from different angles such as category and year. Second, we evaluate the increment influence of newly identified antecedents and report the practical improvement when they are included to predict funding success. Third, we investigate the timeliness of project data and provide evidence that old project data is gradually becoming less relevant and losing predictive power to newly created projects.

\subsection{Descriptive results}

\subsubsection{Overall funding status by category}

Tables 4 and 5 present the status of crowdfunding by category on Kickstarter. Overall, the success rate of our sample projects is $46 \%$, which is comparable to what reported by Kickstarter (Kickstarter 2015). Most of the basic project properties vary across 15 categories. Table 4 shows that in term of project number, the top three categories created are Film \& Video, Music, and Publishing; and the least three are Dance, Craft, and Journalism. However, a project attractive to owners doesn't necessarily mean it is also attractive to backers. For example, Dance is one of the three categories that are least attractive to owners but has the highest success rate among all the categories, possibly because of low fund required and less market saturation (competition). On average, a project requires raising a fund of $\$ 14,541$. Technology and Games require the highest funds, $\$ 39,073$ and $\$ 27,520$, respectively; Music and Crafts require the least funds, \$7289 and \$5794, respectively. It is also reasonable to notice that, generally, project categories requiring higher (lower) funds have lower (higher) success rates. 
Table 4 Previously identified antecedents by category*

\begin{tabular}{|c|c|c|c|c|c|c|c|}
\hline Category & Project & Success & Goal & Success rate & Funding ratio & Backers & Duration \\
\hline Art & 12,255 & 6130 & 9160 & $50 \%$ & 0.84 & 45.82 & 33.10 \\
\hline Comics & 4274 & 2307 & 8466 & $54 \%$ & 1.24 & 147.32 & 35.79 \\
\hline Crafts & 1873 & 633 & 5794 & $34 \%$ & 0.96 & 33.85 & 30.93 \\
\hline Dance & 2064 & 1452 & 7302 & $70 \%$ & 0.89 & 48.19 & 32.71 \\
\hline Design & 8500 & 3585 & 23,385 & $42 \%$ & 1.76 & 280.39 & 34.21 \\
\hline Fashion & 6781 & 2135 & 11,986 & $31 \%$ & 0.73 & 76.97 & 32.68 \\
\hline Film \& video & 34,194 & 15,334 & 20,417 & $45 \%$ & 0.62 & 71.28 & 35.77 \\
\hline Food & 7781 & 2832 & 19,493 & $36 \%$ & 0.67 & 77.85 & 33.76 \\
\hline Games & 10,023 & 4235 & 27,520 & $42 \%$ & 1.85 & 417.15 & 33.39 \\
\hline Journalism & 1101 & 395 & 11,833 & $36 \%$ & 0.53 & 58.91 & 35.14 \\
\hline Music & 28,662 & 16,989 & 7289 & $59 \%$ & 0.81 & 61.90 & 35.71 \\
\hline Photography & 4846 & 1767 & 8179 & $36 \%$ & 0.59 & 46.55 & 34.72 \\
\hline Publishing & 17,117 & 5942 & 9037 & $35 \%$ & 0.61 & 55.14 & 34.28 \\
\hline Technology & 6235 & 1997 & 39,073 & $32 \%$ & 1.28 & 262.84 & 34.83 \\
\hline Theater & 6046 & 4051 & 9178 & $67 \%$ & 0.85 & 53.19 & 33.83 \\
\hline Overall & 151752 & 69784 & 14,541 & $46 \%$ & 0.95 & 115.82 & 34.06 \\
\hline
\end{tabular}

*Because of space limitation, not all previously identified antecedents are listed

Mollick (2014) reports that crowdfunding projects mostly succeed by narrow margins but fail by large amounts. However, we found this is more noticeable in popular categories with a significant number of projects. For example, Untabulated results show that only $3 \%$ of the funded projects in Film \& Video category have a funding ratio greater than 2 (two times the required fund) while that percentage is around $25 \%$ in Comics and design category. Duration has little variation among different categories, with a range from 33 and 36 days, possibly because that Kickstarter has a default duration of 30 days and limits it up to 60 days (it was 90 days before June 2011). Surprisingly, there are some projects have a duration less than 5 days. Further investigation finds they are mostly small project, with funding goals less than $\$ 500$.

Table 5 presents the data related to new antecedents derived from project descriptions. Projects in Games has the longest description (11,24 words) and those in Music has the shortest (453 words). It is also worth noting that the overall readability is high (with Fog index around 13). Possible reason is that comparing to traditional business plans, project descriptions

Table 5 Newly identified antecedents by category

\begin{tabular}{llllll}
\hline Category & Length & Readability & Tone & Past experience & Past expertise \\
\hline Art & 551 & -13.53 & 8.41 & 6.08 & 0.19 \\
Comics & 719 & -12.32 & 6.81 & 15.16 & 0.37 \\
Crafts & 527 & -12.41 & 8.35 & 6.62 & 0.28 \\
Dance & 500 & -14.94 & 10.68 & 5.44 & 0.18 \\
Design & 844 & -12.67 & 7.33 & 9.68 & 0.34 \\
Fashion & 595 & -12.53 & 8.20 & 5.23 & 0.25 \\
Film \& video & 637 & -13.43 & 5.89 & 5.52 & 0.10 \\
Food & 651 & -13.03 & 8.44 & 5.47 & 0.09 \\
Games & 1124 & -12.46 & 8.43 & 18.46 & 0.99 \\
Journalism & 563 & -14.00 & 7.31 & 5.07 & 0.05 \\
Music & 453 & -12.59 & 7.81 & 4.65 & 0.18 \\
Photography & 533 & -13.81 & 7.13 & 5.41 & 0.09 \\
Publishing & 679 & -12.96 & 7.01 & 6.47 & 0.11 \\
Technology & 985 & -13.42 & 7.04 & 6.97 & 0.20 \\
Theater & 503 & -14.22 & 6.68 & 4.81 & 0.14 \\
Overall & 657.67 & -13.22 & 7.70 & 7.40 & 0.24 \\
\hline
\end{tabular}


Table 6 Previously identified antecedents by year*

\begin{tabular}{|c|c|c|c|c|c|c|c|}
\hline Category & Project & Success & Goal & Success rate & Funding ratio & Backers & Duration \\
\hline 2009 & 1145 & 551 & 5846 & $48 \%$ & 0.70 & 36.55 & 58.66 \\
\hline 2010 & 9314 & 4486 & 6857 & $48 \%$ & 0.69 & 42.53 & 46.75 \\
\hline 2011 & 22686 & 11607 & 9242 & $51 \%$ & 0.84 & 59.49 & 40.19 \\
\hline 2012 & 36485 & 17133 & 15,066 & $47 \%$ & 0.86 & 112.89 & 33.41 \\
\hline 2013 & 40975 & 19777 & 17,206 & $48 \%$ & 1.02 & 145.51 & 32.02 \\
\hline 2014 & 41147 & 16230 & 18,483 & $39 \%$ & 0.85 & 111.40 & 31.85 \\
\hline Overall & 151752 & 69784 & 12,117 & $46 \%$ & 0.82 & 84.73 & 40.48 \\
\hline
\end{tabular}

*Because of space limitation, not all previously identified antecedents are listed

are more likely to be written the informal language. Both past experience and past expertise vary greatly across categories, reflecting the different popularity and competition among categories.

\subsubsection{Overall funding status by year}

Tables 6 and 7 present the status of crowdfunding by year on Kickstarter. We find the project properties are relatively more stable over time than across categories. The results show a clear trend that the number of projects and backers and the amount of goal are all increasing over time, though the speed is decreasing. This is reasonable because, as more users join Kickstarter and become more familiar with the platform, more projects are created. In addition, the mutual trust between project owners and backers increases with the familiarity and maturity of Kickstarter platform, thus, more expensive ones are likely to be funded in later years. The results also shows that the durations before 2011 are higher, which is consistent with the fact that Kickstarter allows a duration up to 90 days before June 2011 but reduces to 60 days afterward.

The results in Table 7 show that, although readability and objectivity of project descriptions are relatively stable, project owners are disclosing more information through project description over time, with an exception in 2014. Specifically, the length of project descriptions increases from 405 to 718 words. Another interesting finding is that increasing trend of both past experience and past experiment. As shown in the results, the value of past

Table 7 Newly identified antecedents by year

\begin{tabular}{llllll} 
Category & Lengh & Readability & Tone & Past Experience & Past Expertise \\
\hline 2009 & 405 & -13.03 & 7.14 & 3.65 & 0.03 \\
2010 & 399 & -13.19 & 6.69 & 4.37 & 0.04 \\
2011 & 432 & -13.01 & 7.00 & 6.44 & 0.11 \\
2012 & 593 & -12.90 & 7.38 & 6.62 & 0.14 \\
2013 & 806 & -13.17 & 7.30 & 8.47 & 0.29 \\
2014 & 718 & -13.18 & 7.60 & 8.15 & 0.32 \\
Overall & 558.72 & -13.08 & 7.18 & 6.28 & 0.15 \\
\hline
\end{tabular}

experience increase consistently from 3.65 in 2009 to 8.15 in 2014 , and the value of past expertise also increases consistently from 0.03 in 2009 to 0.32 in 2014. This is reasonable because that, over time, project owners gain experience and expertise by backing and creating more projects, and by making projects more persuasive thus more likely to raise funds.

\subsection{Impact of project descriptions on predicting funding success}

\subsubsection{Logistic regression results}

In order to investigate whether those newly identified antecedents have incremental influence on funding success, we run two logistic models. Model A represents the mainstream model which only includes antecedents identified by previous research from basic project properties (i.e., control variables); Model B represents the proposed model which also includes those exemplary antecedents identified by this study. The results are reported in Table 8 below.

As shown in Model B (proposed model), consistent with unimodel of persuasion, we find antecedents identified from both content of project descriptions (length, readability, and objectivity) and owner traits of project descriptions (pastExperience and pastExpertise) are significantly associated with funding success. Specifically, we find for every $1 \%$ increase of length, the log odds of funding success increases by 0.38 ; this number is 0.68 and 0.58 , for $1 \%$ of increase of past experience and expertise, respectively. We find tone is positively associated with funding success. However, the quadratic term of tone has a negative coefficient, which indicates the curvilinear relationship between tone and funding success. In other words, moderate use of positive tone can demonstrate project owners' confidence and optimism, thus, increases the likelihood of success. Excessive use of positive tone, however, may weaken project's credibility and lead to an adverse effect. The results are consistent with those reported by Parhankangas and Ehrlich (2014). Finally, we find readability is negatively associated with funding success, with $1 \%$ of its increase reduce the log odds by 0.05 . This is puzzling because 
Table 8 Logistic testing results of antecedents

\begin{tabular}{lll}
\hline Antecedents(IVs) & $\begin{array}{l}\text { Model A (Mainstream) } \\
\text { Coefficient (t-statistics) }\end{array}$ & $\begin{array}{l}\text { Model B (Proposed) } \\
\text { Coefficient (t-statistics) }\end{array}$ \\
\hline Intercept & $2.75 * * *(32.51)$ & $-0.27 * * *(-2.64)$ \\
$\log ($ length) & & $0.38^{* * *}(31.84)$ \\
readability & & $-0.05^{* * *}(-19.75)$ \\
tone & & $2.72 * * *(8.99)$ \\
tone & & $-17.85^{*} * *(-9.93)$ \\
$\log$ (pastExperience) & & $0.68 * * *(74.3)$ \\
$\log$ (pastExpertise) & & $0.58^{* * *}(20.75)$ \\
$\log$ (goal) & $-0.6 * * *(-113.18)$ & $-0.64 * * *(-110.02)$ \\
duration & $-0.01 * * *(-30.69)$ & $-0.01 * * *(-26.25)$ \\
$\log$ (rewards) & $1.24 * * *(83.12)$ & $0.97 * * *(61.64)$ \\
$\log$ (FBFriends) & $0.04 * * *(21.79)$ & $0.01 * * *(5.85)$ \\
$\log$ (numImages) & $0.28 * * *(41.18)$ & $0.11 * * *(14.21)$ \\
$\log$ (numVideos) & $0.83^{* * *}(42.18)$ & $0.7 * * *(34.23)$ \\
year & controlled & controlled \\
category & controlled & controlled \\
Pseudo R-square $(\%)$ & 17.16 & 22.98 \\
\hline
\end{tabular}

**, *** statistically significant at $5 \%$ and $1 \%$, respectively

we expect a positive association since a more readable project description is easier to be understood by potential backers. However, as discussed in the descriptive statistics section, project descriptions are mainly written in informal language with low Fog index (easy to understand). Under this circumstances, formally written project descriptions may signal the preparedness and professionalism of project owners (Chen et al. 2009), thus increase the positive perception of backers and increase the likelihood of funding success. Similar results have also been reported by a previous study (Luo et al. 2013).

The results of other antecedents are consistent between Model A and B. For example, a higher requirement of funding goal and a longer campaign duration are negatively associated with funding success; a higher number of reward levels has a positive influence on funding success; and as expected, a higher number of Facebook friends, images, and videos are also positively associated with funding success.

\subsubsection{Evaluation of predicting performance}

We first compare the predicting performance of our proposed model (Model B) with the mainstream model (Model A) discussed above. We use the entire data sample to train (via logistic models) and test the predicting performance. In addition to the accuracy rate, we also use F-measure to evaluate the prediction performance. F-measure considers both prediction accuracy and recall accuracy and thus provides a balanced performance evaluation (Ferri et al. 2009; Sokolova and Lapalme 2009; Powers 2011). The results are reported in Table 9.
As shown in Table 9 Panel B, the proposed model has a predicting accuracy (F-measure) of $73.09 \%(70.31 \%)$, while the mainstream model has a predicting accuracy (F-measure) of $69.34 \%(66.20 \%)$. This indicates the proposed model has a better performance of predicting funding success. In addition, the confusion matrixes of both models further demonstrate that proposed model has higher true positive and true negate rates $(69.3 \%$ and $76.32 \%)$ than those rates $(65.28 \%$ and 72.79) of the mainstream model. Correspondingly, the proposed model has a lower false positive and false negative rates $(23.68 \%$ and $30.7 \%)$ than those rates $(27.21 \%$ and 34.72$)$ of the mainstream model. These results show that the newly identified antecedents have incremental predictive power.

However, training and testing a predictive model using the same data sample is not a good practice. A recommended practice is to use different datasets to train and test the model (Bengio and Grandvalet 2004). In this step, besides the proposed and mainstream model, we include another model called baseline model. Baseline model is based on informed guessing. In baseline model, we classify each project as "success" or "failure" simply according to the overall probability of funding success. For example, if $40 \%$ projects are successfully funded, the overall probability of funding success is $40 \%$. Therefore, each project will be classified as "success" with a probability of $40 \%$ and to "failure" with a probability of $60 \%$. Then we calculate the prediction performance by comparing projects' assigned status values (i.e., success or failure) with their true status values.

For each predictive model, we employ $\mathrm{N}$-fold cross-validation test (with $\mathrm{N}$ set as 3,5 and 10) to evaluate the prediction performance. The $\mathrm{N}$-fold cross-validation test has been widely used to validate the performance of classification (Bengio and Grandvalet 2004; Li 2008). For each N, our data sample is randomly divided into $\mathrm{N}$ parts, then $\mathrm{N}$ experiments are performed, with $\mathrm{N}-1$ parts used as training data for the predictive model to classify the remaining part. The average prediction performance is reported for the given N. Our results of $\mathrm{N}$-fold cross-validation test are reported in Table 10.

The results show that our proposed model achieves the highest performance, with the average accuracy rate (Fmeasure) around $73 \%(70 \%)$. The average accuracy rate (Fmeasure) of the mainstream model is around $69 \%(66 \%)$, and baseline model around $59 \%(57 \%)$. This indicates that the proposed model has an improvement of roughly 14 percentage points over the baseline model based on informed guessing and 4 percentage points improvement over the mainstream model based on basic project properties. The differences among these three models are statistically significant under the t-test. More importantly, considering that the mainstream model only beats the baseline model by 9 percentage points ( $66 \%$ vs. $57 \%$ ), the 4 additional percentage points ( $70 \%$ vs. $66 \%$ ) improved by our proposed model is fair significant, representing $44 \%$ (i.e., 4 divided by 9) of mainstream's performance over informed 
Table 9 Performance measures and confusion matrix

\begin{tabular}{|c|c|c|c|c|}
\hline Panel A & \multicolumn{4}{|c|}{ Model A (Mainstream Model) } \\
\hline Accuracy: & $69.34 \%$ & & F-Measure: & $66.20 \%$ \\
\hline & \multicolumn{4}{|c|}{ Predicted } \\
\hline & & Failed & Success & Total \\
\hline \multirow[t]{3}{*}{ Actual } & Failed & $\mathrm{TN}=59666(72.79 \%)$ & $\mathrm{FP}=22302(27.21 \%)$ & 81968 \\
\hline & Success & $\mathrm{FN}=24226(34.72 \%)$ & $\mathrm{TP}=45558(65.28 \%)$ & 69784 \\
\hline & Total & 83892 & 67860 & 151752 \\
\hline Panel B & \multicolumn{4}{|c|}{ Model B (Proposed Model) } \\
\hline \multirow[t]{3}{*}{ Accuracy: } & $73.09 \%$ & & F-Measure: & $70.31 \%$ \\
\hline & \multicolumn{4}{|c|}{ Predicted } \\
\hline & & Failed & Success & Total \\
\hline \multirow[t]{3}{*}{ Actual } & Failed & $\mathrm{TN}=62,556(76.32 \%)$ & $\mathrm{FP}=19412(23.68 \%)$ & 81968 \\
\hline & Success & $\mathrm{FN}=21426(30.7 \%)$ & $\mathrm{TP}=48358(69.3 \%)$ & 69784 \\
\hline & Total & 83982 & 67770 & 151752 \\
\hline
\end{tabular}

guessing. These results together show that our newly introduced variables have significant and practical impacts on the funding success of projects.

Both accuracy and F-measure are designed for the overall performance of predictive models. Sometimes, however, we need more specific information to make the funding decision. This is especially true when we evaluate prediction performance from the perspective of project owners. Because of the limited time and resources, project owners may not be interested in the overall success rate. Instead, they care more about whether their projects, if predicted as success, will truly be successfully funded. In another word, they want a predictive model that has high true positive rate and low false positive rate. Although this has been reported in the confusion matrixes, one of the visual illustration is to use ROC (Receiver Operating Characteristic) curve, which plots the true positive rate against the false positive rate at various threshold settings (Fawcett 2006). The results are illustrated in Fig. 1.

As shown in Fig. 1, comparing to the mainstream model, our proposed model has an ROC curve more convex toward upper-left. This indicates that the proposed model has a higher true positive rate and a lower false positive rate, which is more useful for project owners to change their project settings and evaluate the likelihood of funding success before projects are launched.

Table 10 N-Fold Cross-validation tests accuracy (F-Measure)

\begin{tabular}{llll}
\hline $\mathrm{N}$ & Baseline (\%) & Mainstream (\%) & Proposed (\%) \\
\hline 3 & $59.34(57.26)$ & $69.21(66.58)$ & $73.36(70.59)$ \\
5 & $59.67(57.19)$ & $69.36(66.15)$ & $73.28(71.32)$ \\
10 & $59.83(57.68)$ & $69.67(66.49)$ & $73.19(70.43)$ \\
\hline
\end{tabular}

\subsection{Predictive power of project data over time}

In the previous subsections, in order to ensure the comparability, we follow the previous studies and conduct our analysis by ignoring the temporal (i.e., time) information of projects. In other words, all projects are put in a single pool and predictions are in both directions: older project data are used to predict newer projects and, at the same time, newer projects are used to predict older projects. This can be clearly seen from our $\mathrm{N}$ fold cross-validation test, in which the total sample is randomly divided into $\mathrm{N}$ parts without considering the creating time of each project. When we predict a funding success of a project, however, the only project data available to make a prediction is those historical data before the one being predicted, and it seems unreasonable to use future project data to train the predictive model and predict the funding success of past projects.

On the other hand, as a new platform of crowdfunding, Kickstarter has experienced great changes since its inception, from perspectives such as system functions, platform policy, and so on. In addition, both backers and owners have changed their behaviors greatly though their use of the crowdfunding platform. Furthermore, the number of users and projects grow drastically over time, which changes the competition environment of crowdfunding. These changes make us wonder whether the project data in earlier years have become "out of date" and have less predictive power to future project success, and whether the sub-sample of project data right before the projects being predicted contains the most relevant information and have higher predictive power. 
Fig. 1 The ROC curves of baseline, mainstream, and proposed models

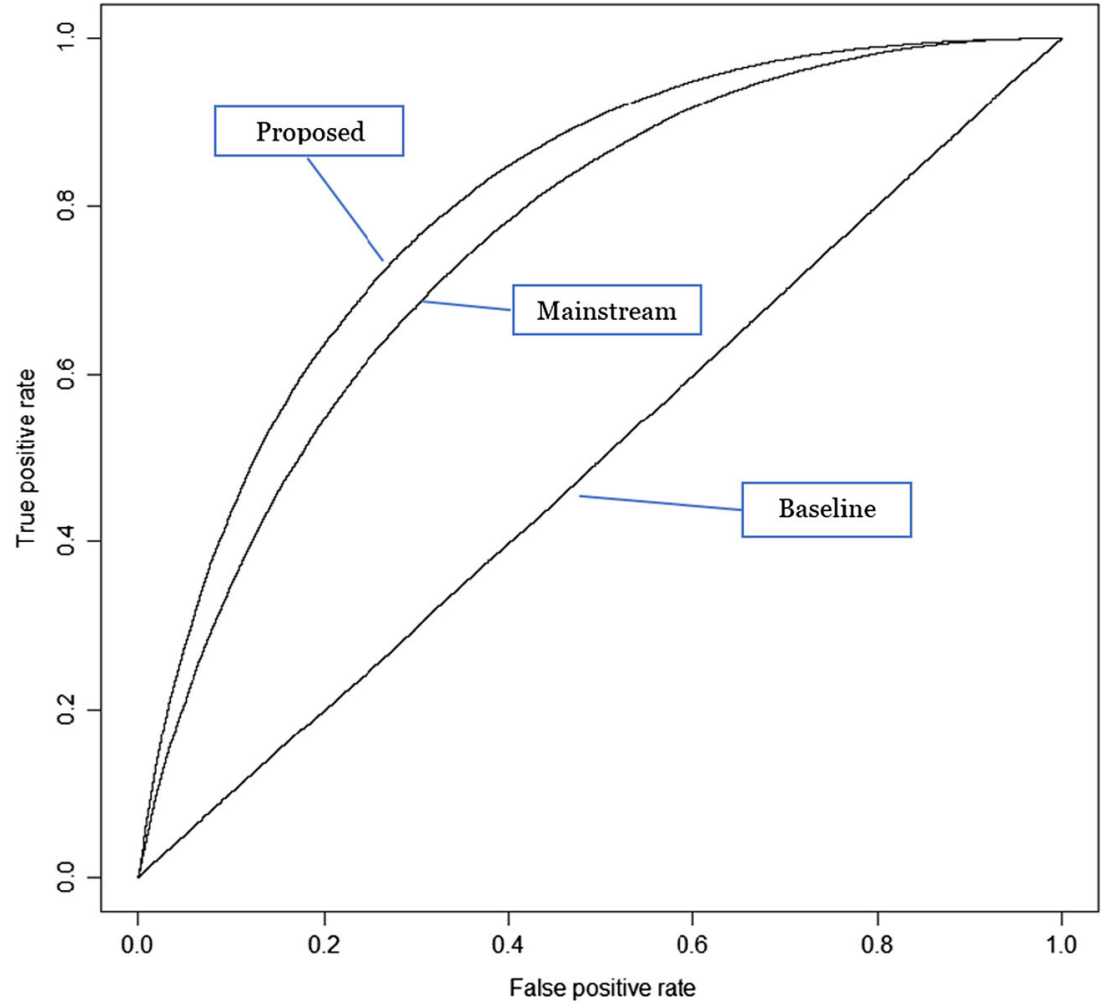

In order to answer these questions, we slice the whole sample (2009 to 2014) by month and construct narrower, but relatively big enough subsample (e.g., 6 or 12 month $^{4}$ ) and analyze the effectiveness of project data of different subsamples on prediction performance. We construct six subsamples consisting of one year's project data from 2009 to June, 2014 (the last sub-sample contains only 6 month's data), each of these sub-samples is used as training data to predict the funding success of projects between July and November of 2014 (our data sample ends in November 2014).

Figure 2 presents the results of the prediction performance (F-measure) by using each year's data from 2009 to 2014. Consistent with our conjectures, we find that, overall, the prediction performance increases over time for both mainstream and proposed models. We remove the informed guessing model from this analysis because its performance only depends on the success rate of each year, which increases and then decrease as evidenced in Table 6. The figure indicates there are two bigger jumps in the year 2010 and 2014. In addition to the reason that project data in 2009 is the oldest relative to projects in 2014, another possible reasons is that, since Kickstarter was funded in 2009, the project data in 2009 may contains more noises and inconsistency. These two reasons together may result in the prediction performance by using data of 2009 is

\footnotetext{
${ }^{4}$ The length (number of months) can be changed accordingly, if necessary.
}

"much" lower than other years. The performance jump in 2014, on the other hand, may mainly reflect the timeliness of data because the first half year's project data is used as training data to predict the projects of the second half year. The results also show that, from 2010 to 2013, although the improvement is relatively small, the overall trend of prediction performance is obviously increasing. These results together provide evidence that the historical project data is gradually becoming less relevant and losing predictive power to newly created projects. We also replace the F-measure with the accuracy rate and find the similar pattern.

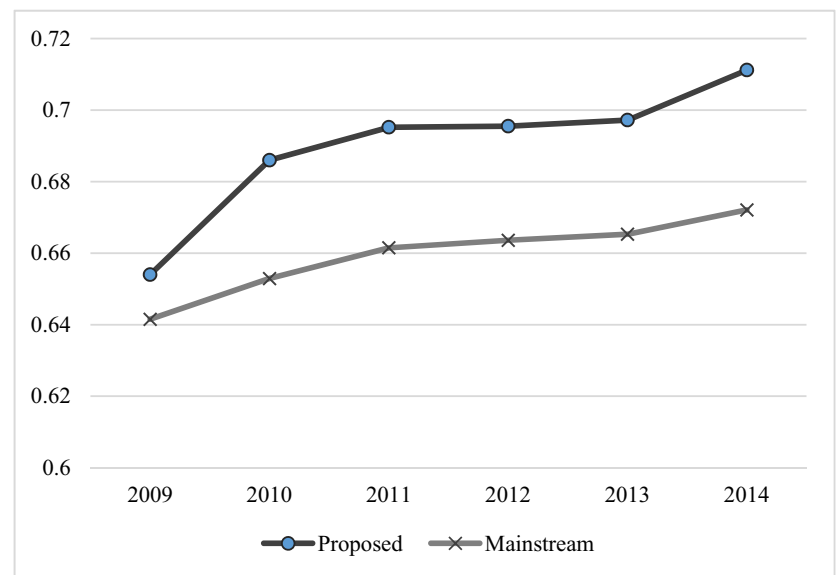

Fig. 2 The timeliness of project data on predicting performance (FMeasure) 


\section{Conclusions and discussions}

The success of crowdfunding warrants its importance of research, and we expect an increasing use of crowdfunding in future venture investment. By using a large dataset obtained from Kickstarter, a popular crowdfunding platform, we examine the influence of project descriptions on funding success. To do so, we rely on the unimodel of persuasion and identify five exemplary antecedents from project descriptions: three of them are related to the content of project descriptions and two of them are related to the owner traits of project descriptions. We then investigate the influence of these antecedents by using logistic model. Our results show that the proposed model can predict funding success with an accuracy rate of $73 \%$ (or $70 \%$ in F-measure), which represents an improvement of roughly 14 percentage points over the baseline model based on informed guessing and 4 percentage points improvement over the mainstream model based on basic project properties (or $44 \%$ improvement of mainstream's performance over informed guessing). These results together show that those antecedents identified from project descriptions have significant and practical impacts on the funding success of projects. We also investigate the timeliness of project data and provide evidence that old project data is gradually becoming less relevant and losing predictive power to newly created projects.

This paper contributes to the crowdfunding literature in several ways. First, to the best of our knowledge, this study is among the first to explore crowdfunding with a focus on the information content of project descriptions. Second, this paper is also among the first to introduce communication theory in general and persuasion theory in particular (i.e., unimodel) into the crowdfunding context. Using content analysis, we measure the influence of project descriptions and investigate its impacts on funding success. The newly identified antecedents from project descriptions can then be used in different predictive models to enhance the predicting performance. Third, the results reported in this paper highlight the importance of project descriptions and provide insights for project owners to understand the influence of antecedents and increase their funding success with proper balance among antecedents. Fourth, existing predictive models of funding success usually employ overall accuracy to measure performance (Etter et al. 2013; Greenberg et al. 2013; Mitra and Gilbert 2014). Our proposed model is also evaluated using more balanced performance measures (i.e., F-measure and ROC curve) to better serve backers to make funding decisions. Taken together, our results provide meaningful insights to researchers, project owners, and backers to better understand the importance of project descriptions and their influence on funding success.

This study is subject to several limitations. First, we conduct our studies merely base on one crowdfunding platform. There are other popular platforms (e.g., IndieGoGo) with different rules. This limits the generalizability of our results.
Second, we mainly consider the information communicated between owners and backers through the crowdfunding platform (within-platform activities). There are many channels of "offline" communication and interactions between owners and backers (off-platform activities) such as media coverage, which are also critical to funding success. Third, we limit our study to the information content of project description before project launch. The information content of project updates and comments after project launch are also important to funding success. Fourth, we simply exclude cancelled projects from our study, which may cause our results biased.

This study also provides valuable opportunities for future research. First, some of the limitations can be addressed in future research. Future research can compare different crowdfunding platforms and gain more insights. Kickstarter and IndieGoGo have different rules regarding how to keep funds raised. These difference may lead to different motivations when selecting platform and different strategies when preparing the campaign. This study can also be extended to the stage after the project is launched and provide real-time monitoring and suggestions to increase funding success for project owners. Second, future studies can examine the influence of project descriptions by using more advanced features such as linguistic structures or methodologies such as topic modeling. Third, our study is conducted at a broader level to identify antecedents beyond basic project properties. Future study can further focus on a single antecedent and provide us with more thorough understanding. For example, Zvilichovsky et al. (2015) focus on past experience and find there exist a reciprocity effect on crowdfunding. Similar studies can be conducted based on other antecedents such as tone and readability. Fourth, with the fast growing of crowdfunding projects, it is becoming increasingly difficult for a project owner to attract enough backers and for a backer to choose a suitable project. Future research can work on bringing the two types of participants closer by identifying potential backers to owners or recommending potential projects to backers. Fifth, the main purpose of this study is to highlight the important influence of project descriptions and identify exemplary antecedents. In order to further improve the prediction performance, future research can incorporate those new antecedents into other classification models such as decision trees and Support Vector Machine (SVM), which provide better model calibration. Sixth, cancelled projects are excluded from study, which may make our results biased. Cancelled projects count for around $8 \%$ of our data sample, they are mainly "perceived as failed" by project owners. Kickstarter allows project owners to cancel a project during and even after the campaign is ended. However, we know little regarding the influence of cancellation on project owners, backers and the general crowdfunding practice. Last but not least, the theory and methodology used in this study can be extended and applied to equity-based crowdfunding domain. We encourage future research to explore these areas and advance our knowledge in crowdfunding. 
Acknowledgements This research is supported by Center for Business Intelligence and Analytics (CIBA) at Virginia Tech and the Natural Science Foundation of China (Grant No. 71531013).

This research is also supported by the Ministry of education of Humanities and Social Science project (Grant No. 13YJC630105) and the Fundamental Research Funds for the Central Universities (Grant No. 16CX05004B).

Open Access This article is distributed under the terms of the Creative Commons Attribution 4.0 International License (http:// creativecommons.org/licenses/by/4.0/), which permits unrestricted use, distribution, and reproduction in any medium, provided you give appropriate credit to the original author(s) and the source, provide a link to the Creative Commons license, and indicate if changes were made.

\section{References}

Abrahams, A. S., Fan, W., Alan Wang, G., Zhang, Z. J., \& Jiao, J. (2014). An integrated text analytic framework for product defect discovery. Production and Operations Management. doi:10.1111/poms. 12303.

Agrawal, D., Bernstein, P., Bertino, E., Davidson, S., Dayal, U., Franklin, M., ... Han, J. (2011). Challenges and Opportunities with Big Data 2011-1. Retrieved from http://docs.lib.purdue.edu/cctech/1/.

Baron, R. A. (2008). The role of affect in the entrepreneurial process. Academy of Management Review, 33(2), 328-340. doi:10.5465/ AMR.2008.31193166

Baum, J. R., Locke, E. A., \& Smith, K. G. (2001). A multidimensional model of venture growth. Academy of Management Journal, 44(2), 292-303. doi:10.2307/3069456.

Belleflamme, P., Lambert, T., \& Schwienbacher, A. (2014). Crowdfunding: tapping the right crowd. Journal of Business Venturing, 29(5), 585-609. doi:10.1016/j.jbusvent.2013.07.003.

Bengio, Y., \& Grandvalet, Y. (2004). No unbiased estimator of the variance of $\mathrm{k}$-fold cross-validation. The Journal of Machine Learning Research, 5, 1089-1105.

Catellani, P., \& Alberici, A. I. (2012). Does the candidate matter? Comparing the voting choice of early and late deciders. Political Psychology, 33(5), 619-634. doi:10.1111/j.1467-9221.2012.00891.x.

Chan, C. S. R., \& Park, H. D. (2015). How images and color in business plans influence venture investment screening decisions. Journal of Business Venturing, 30(5), 732-748. doi:10.1016/j. jbusvent.2014.12.002.

Chen, X.-P., Yao, X., \& Kotha, S. (2009). Entrepreneur passion and preparedness in business plan presentations: a persuasion analysis of venture capitalists' funding decisions. Academy of Management Journal, 52(1), 199-214.

Davis, A. K., Ge, W., Matsumoto, D., \& Zhang, J. L. (2012). The effect of managerial "style" on the tone of earnings conference calls. In CAAA Annual Conference. Retrieved from http://www.usc. edu/schools/business/FBE/seminars/papers/ARF_9-21-12_GE.pdf.

Etter, V., Grossglauser, M., \& Thiran, P. (2013). Launch hard or go home!: Predicting the success of kickstarter campaigns. In Proceedings of the first ACM conference on online social networks (pp. 177-182). New York, NY, USA: ACM. doi: 10.1145/ 2512938.2512957.

Fawcett, T. (2006). An introduction to ROC analysis. Pattern Recognition Letters, 27(8), 861-874. doi:10.1016/j.patrec.2005.10.010.

Ferri, C., Hernández-Orallo, J., \& Modroiu, R. (2009). An experimental comparison of performance measures for classification. Pattern Recognition Letters, 30(1), 27-38. doi:10.1016/j. patrec.2008.08.010.

Greenberg, M. D., Pardo, B., Hariharan, K., \& Gerber, E. (2013). Crowdfunding support tools: predicting success \& failure. In
CHI'13 Extended Abstracts on Human Factors in Computing Systems (pp. 1815-1820). ACM. Retrieved from http://dl.acm. org/citation.cfm?id=2468682.

Gunning fog index. (2015). In Wikipedia, the free encyclopedia. Retrieved from http://en.wikipedia.org/w/index.php?title= Gunning_fog_index\&oldid=645516106.

Hua, Z., Wang, Y., Xu, X., Zhang, B., \& Liang, L. (2007). Predicting corporate financial distress based on integration of support vector machine and logistic regression. Expert Systems with Applications, 33(2), 434-440. doi:10.1016/j.eswa.2006.05.006.

Huang, X., Teoh, S. H., \& Zhang, Y. (2013). Tone Management. The Accounting Review, 89(3), 1083-1113. doi:10.2308/accr-50684.

IndieGoGo. (2014). Learn More | Indiegogo. Retrieved January 14, 2015, from https://www.indiegogo.com/learn-how-to-raise-money-for-acampaign.

Kickstarter. (2014a). Kickstarter Basics » Frequently Asked Questions (FAQ) - Kickstarter. Retrieved January 14, 2015, from https://www.kickstarter.com/help/faq/kickstarter\%20basics.

Kickstarter. (2014b). Kickstarter Stats — Kickstarter. Retrieved January 14, 2015, from https://www.kickstarter.com/help/stats.

Kickstarter. (2015). Kickstarter Stats - Kickstarter. Retrieved October 14, 2015, from https://www.kickstarter.com/help/stats.

Kickstarter. (2016). Creator Questions » Frequently Asked Questions (FAQ) - Kickstarter. Retrieved July 10, 2016, from https://www. kickstarter.com/help/faq/creator+questions.

Kruglanski, A. W. (1989). Lay epistemics and human knowledge: Cognitive and motivational basesPlenum press. New York: Plenum.

Kruglanski, A. W., Chen, X., Pierro, A., Mannetti, L., Erb, H.-P., \& Spiegel, S. (2006). Persuasion according to the unimodel: implications for cancer communication. Journal of Communication, 56, S105-S122. doi:10.1111/j.1460-2466.2006.00285.x.

Kuppuswamy, V., \& Bayus, B. L. (2013). Crowdfunding creative ideas: The dynamics of project backers in kickstarter. SSRN electronic journal. Retrieved from http://funginstitute.berkeley. edu/sites/default/files/V.Kuppuswamy_Crowdfunding $\% 20-\% 20$ UCBerkeley.pdf.

Kuppuswamy, V., \& Bayus, B. L. (2015). Crowdfunding creative ideas: The dynamics of project backers in Kickstarter. UNC Kenan-Flagler Research Paper, (2013-15). Retrieved from http://papers.ssrn. com/sol3/Papers.cfm?abstract_id=2234765.

Li, F. (2008). Annual report readability, current earnings, and earnings persistence. Journal of Accounting and Economics, 45(2-3), 221247. doi:10.1016/j.jacceco.2008.02.003.

Li, Z., \& Duan, J. A. (2014). Dynamic strategies for successful online crowdfunding. Available at SSRN 2506352. Retrieved from http://papers.ssrn.com/sol3/Papers.cfm?abstract id=2506352.

Luo, C., Luo, X. R., Schatzberg, L., \& Sia, C. L. (2013). Impact of informational factors on online recommendation credibility: the moderating role of source credibility. Decision Support Systems, 56, 92-102. doi:10.1016/j.dss.2013.05.005.

Massolution. (2015). 2015CF - Crowdfunding Industry Report. Retrieved January 15, 2016, from http://www.crowdsourcing. org/editorial/globalcrowdfunding-market-to-reach-344b-in-2015predicts-massolutions-2015cf-industry-report/45376.

Mitra, T., \& Gilbert, E. (2014). The language that gets people to give: Phrases that predict success on kickstarter. In Proceedings of the 17th ACM Conference on Computer Supported Cooperative Work \&\#38; Social Computing (pp. 49-61). New York, NY, USA: ACM. doi: $10.1145 / 2531602.2531656$.

Mollick, E. (2014). The dynamics of crowdfunding: an exploratory study. Journal of Business Venturing, 29(1), 1-16. doi:10.1016/j. jbusvent.2013.06.005.

needwant.com. (2016). Why we cancelled our kickstarter and funded it ourselves. Retrieved July 14, 2016, from http://needwant. $\mathrm{com} / \mathrm{p} /$ cancelled-kickstarter-campaign-funded-project-ourselves/. 
Ordanini, A., Miceli, L., Pizzetti, M., \& Parasuraman, A. (2011). Crowdfunding: transforming customers into investors through innovative service platforms. Journal of Service Management, 22(4), 443-470. doi:10.1108/09564231111155079.

Parhankangas, A., \& Ehrlich, M. (2014). How entrepreneurs seduce business angels: an impression management approach. Journal of Business Venturing, 29(4), 543-564. doi:10.1016/j. jbusvent.2013.08.001.

Petty, R. E., \& Cacioppo, J. T. (1986). The elaboration likelihood model of persuasion. Advances in Experimental Social Psychology, 19, 123-205.

Petty, R. E., Priester, J. R., \& Brinol, P. (2002). Mass media attitude change: implications of the elaboration likelihood model of persuasion. Media Effects: Advances in Theory and Research, 2, 155-198.

Powers, D. M. (2011). Evaluation: from precision, recall and F-measure to ROC, informedness, markedness and correlation. .Retrieved from http://dspace2.flinders.edu.au/xmlui/handle/2328/27165

Rucker, D. D., \& Petty, R. E. (2006). Increasing the effectiveness of communications to consumers: recommendations based on elaboration likelihood and attitude certainty perspectives. Journal of Public Policy \& Marketing, 25(1), 39-52. doi:10.1509/jppm.25.1.39.

Sokolova, M., \& Lapalme, G. (2009). A systematic analysis of performance measures for classification tasks. Information Processing \& Management, 45(4), 427-437. doi:10.1016/j.ipm.2009.03.002.

stonemaiergames.com. (2013, August 26). Kickstarter Lesson \#49: To Cancel or to Finish. Retrieved from http://stonemaiergames. com/kickstarter-lesson-49-to-cancel-or-to-finish/.

Suárez-Vázquez, A., \& Quevedo, J. R. (2015). Analyzing superstars' power using support vector machines. Empirical Economics, 49(4), 1521-1542. doi:10.1007/s00181-015-0923-1.

Sun, Y., Lim, K. H., Jiang, C., Peng, J. Z., \& Chen, X. (2010). Do males and females think in the same way? An empirical investigation on the gender differences in web advertising evaluation. Computers in Human Behavior, 26(6), 1614-1624. doi:10.1016/j.chb.2010.06.009.

themarysue.com. (2016). \$122,874 Kickstarter-funded board game cancelled, what happens to the money? Retrieved from http://www. themarysue.com/kickstarter-board-game-failure/.

Venkatraman, V., Dimoka, A., Pavlou, P. A., Vo, K., Hampton, W., Bollinger, B., et al. (2014). Predicting advertising success beyond traditional measures: new insights from neurophysiological methods and market response modeling. Journal of Marketing Research, 52(4), 436-452. doi:10.1509/jmr.13.0593.

Wang, G., Liu, X., \& Fan, W. (2011). A knowledge adoption model based framework for finding helpful user-generated contents in online communities. Proceedings of 2011 international conference on information syst ems. Retrieved from http://aisel.aisnet.org/icis2011/ proceedings/knowledge/15/.

Wikipedia. (2015). Flesch-Kincaid readability tests. In Wikipedia, the free encyclopedia. Retrieved from http://en.wikipedia.org/w/index. php?title $=$ Flesch\%E2\%80\%93 Kincaid readability tests\&oldid $=663071728$.

Xu, A., Yang, X., Rao, H., Fu, W.-T., Huang, S.-W., \& Bailey, B. P. (2014). Show me the money!: An analysis of project updates during crowdfunding campaigns. In Proceedings of the SIGCHI conference on human factors in computing systems (pp. 591-600). New York, NY, USA: ACM. doi:10.1145/2556288.2557045.

Zhou, M., Du, Q., Zhang, X., Qiao, Z., Wang, G., \& Fan, W. (2015). Money talks: A predictive model on crowdfunding success using project description. AMCIS 2015 Proceedings. Retrieved from http://aisel.aisnet. org/amcis2015/BizAnalytics/GeneralPresentations/37.

Zvilichovsky, D., Inbar, Y., \& Barzilay, O. (2015). Playing both sides of the market: success and reciprocity on crowdfunding platforms. Available at SSRN 2304101. Retrieved from http://papers.ssrn. com/abstract=2304101.
Mi (Jamie) Zhou is a Ph.D. student in Accounting and Information Systems at Virginia Tech. His research interests include Big Data Analytics, Corporate Disclosures, and Capital Markets. He has published papers in a variety of journals and conferences. Jamie received his master degrees in Accounting and Computer Science from UNC Charlotte, and bachelor degree in Computer Science from the Xi'an Jiaotong University. He started his career with IBM and AmerisourceBergen Corporation as a software engineer. He also worked as a consultant/Senior Consultant at Deloitte for three years.

Baozhou Lu is an associate professor in School of Economics \& Management at China University of Petroleum. He earned his Ph.D from Louisiana State University. His primary research interests focus on ecommerce, online microsourcing, IT impacts on organizational changes and emerging technologies. Publications on these topics appear in Decision Support Systems, Computers in Human Behavior, Electronic Commerce Research and Applications, Information Systems Frontiers, among others.

Weiguo (Patrick) Fan is a R. B. Pamplin Endowed Chair Professor of Accounting and Information Systems, Full Professor of Computer Science (courtesy) and fellow of the Center for Business Intelligence and Analytics at Virginia Tech. He received his Ph.D. in Business Administration from the Ross School of Business, University of Michigan, Ann Arbor, in 2002, a M. Sce in Computer Science from the National University of Singapore in 1997, and a B. E. in Information and Control Engineering from the Xi' an Jiaotong University, P.R. China, in 1995. His research interests focus on the design and development of novel information technologies - information retrieval, data mining, text/web mining, business intelligence techniques - to support better business information management and decision making. He has published more than 160 refereed journal and conference papers. His research has appeared (or will appear) in journals such as Information Systems Research, Journal of Management Information Systems, Production and Operations Management, IEEE Transactions on Knowledge and Data Engineering, Information Systems, Communications of the ACM, Information and Management, Journal of the American Society on Information Science and Technology, Information Processing and Management, Decision Support Systems, ACM Transactions on Internet Technology, Pattern Recognition, IEEE Intelligent Systems, Information Sciences, Journal of Informetrics, Information Systems Frontiers, Journal of Computer Information Systems, Pattern Recognition Letters, International Journal of e-Collaboration, and International Journal of Electronic Business, Chinese Management Studies. His research has been cited more than 4900 times according to Google Scholar. His research has been funded by five NSF grants, two China NSF grants, one PWC grant, and one KPMG grant.

G. Alan Wang is an Associate Professor in the Department of Business Information Technology. He received the Ph.D. in Management Information Systems from the University of Arizona, the M.S. in Industrial Engineering from Louisiana State University, and the B.E. in Industrial Management \& Engineering from Tianjin University. His research interests include social media analytics, business intelligence, text mining, data mining and knowledge discovery, and decision support systems. He has published in Productions and Operations Management, Journal of Business Ethics, Decision Support Systems, Communications of the ACM, IEEE Transactions of Systems, Man and Cybernetics (Part A), IEEE Computer, and Group Decision and Negotiation. Dr. Wang is a member of the Association for Information Systems (AIS), the INFORMS, and the Institute of Electrical and Electronics Engineers (IEEE). 